Artículos

\title{
Observatorio en la mira: consideraciones teórico-metodológicas sobre el seguimiento del conflicto laboral
}

Observatory in the spotlight: theoretical-methodological considerations on the monitoring of labour conflict

Patricia Collado

DOI: https://doi.org/10.24215/18537863e069

Instituto de Ciencias Sociales Humanas y Ambientales

INCIHUSA CCT-Mendoza, CONICET/Facultad de

Ciencias Politicas y Sociales - Universidad Nacional de

Cuyo, Argentina

pcollado@mendoza-conicet.gob.ar

C. Beatriz Soria

Facultad de Ciencias Politicas y Sociales - Universidad

Nacional de Cuyo/ CONICET-Facultad de Ciencias

Sociales-Universidad Nacional de San Juan. Instituto de

Investigaciones Socio Económicas (IISE), Argentina

soriabeatriz@yahoo.com.ar

Recepción: 28 Mayo 2019

Aprobación: 19 Diciembre 2019

\section{Resumen:}

El presente artículo es parte del desarrollo del Observatorio de Conflictividad Laboral de la Provincia de Mendoza. Nuestro objetivo es abocarnos a uno de sus aspectos más relevantes, a saber, la articulación de diversos niveles de abstracción en la selección de categorías analíticas, variables y dimensiones. Desde el Configuracionismo Latinoamericano, trabajamos primero con el sentido del conflicto (abstracto), luego abordamos la formación social mendocina (concreto histórico) para finalmente considerar la importancia de la determinación de acciones conflictivas públicas que indican formas de subjetivación política. Este recorrido aporta una reflexión epistemológica-teórica e histórica acerca de la herramienta puesta en marcha en función del seguimiento sistemático de la conflictividad social.

Palabras Clave: Observatorio, Conflicto, Trabajo, Mendoza.

\section{Abstract:}

This article is part of the development of the Labor Conflict Observatory of the Province of Mendoza. Our main objective is to focus on one of its most relevant aspects: articulation of different levels of abstraction in the selection of analytical categories, variables and dimensions. From the Latin American Configurationism, we first work with the sense of conflict (abstract), then we approach Mendoza"s social formation (historical concrete) to finally consider the importance of the determination of public conflictive actions that indicate forms of political subjectivation. This route provides an epistemological-theoretical and historical reflection about the tool set in motion based on the monitoring of social conflict.

KeYwoRDs: Observatory, Conflict, Work, Mendoza.

\section{INTRODUCCIÓN}

Este escrito presenta algunas reflexiones teóricas-metodológicas producto de un trabajo de investigación sobre el conflicto capital-trabajo -que cumple diez años de existencia- denominado Observatorio de Conflictividad Sociolaboral de la Provincia de Mendoza. ${ }^{1}$ El acercamiento al conflicto representa una forma sintética de ponderar, evaluar y reflexionar sobre la situación estructural del trabajo, en relación a la dinámica de acumulación del capital, con el foco puesto en la disputa que se expresa en el espacio público. El Estado y los medios de comunicación (como fuente de información y partícipes de la construcción del litigio) conforman 
una constelación de relaciones densas que complejizan paulatinamente el análisis del proceso en cuestión y su interpretación.

Para la construcción de este instrumento recuperamos centralmente los antecedentes y aportes de la historia reciente (Izaguirre y Aristizábal, 2002), del PIMSA -Programa de Investigación sobre el Movimiento de la Sociedad Argentina- (Iñigo Carrera y Podestá, 1997; Iñigo Carrera y Cotarelo, 2001), del campo de los estudios sobre movimientos sociales y acción colectiva (GEPSAC -Grupo de Estudios sobre Protesta y Acción Colectiva-IIGG-UBA-, Programa de Estudios sobre Acción Colectiva y Conflicto Social-UNC), y las contribuciones de otros registros sistemáticos tales como el Observatorio del Derecho Social de CTA, Base de Conflictos Laborales del ex Ministerio de Trabajo Empleo y Seguridad Social, Base de datos de conflictos laborales-CEI-UNQ.

El Observatorio podría ser tomado como una estrategia de índole cuantitativa, que se basa en el seguimiento cotidiano de noticias publicadas en la prensa gráfica sobre los conflictos protagonizados por trabajadores. Sin embargo -y por eso presentamos este trabajo aquí-, es mucho más que una herramienta de construcción de datos, ya que su realización supone desarrollar diversas capacidades, perspectivas y técnicas para su constitución, sistematización y posterior análisis. El conocimiento de la economía regional, las tradiciones de lucha del movimiento obrero, la estructura social mendocina y su dinámica (en términos poblacionales y de mercado de trabajo), los modos en que el Estado ha asumido la cuestión social en general y en particular los procesos de conflicto son algunos de los campos de estudios sociales que se ponen en juego. A ello se suma el seguimiento de nuestras líneas de investigación particulares, que, desde los estudios de caso, observaciones, análisis documental y testimonios, aportan densidad interpretativa y conforman una referencia ineludible para comprender el "dato duro". Aun con esto, nuestro objetivo pretende avanzar un poco más. Intentamos llenar de "carnadura" teórica las disquisiciones metodológicas que el Observatorio ha suscitado, más allá de sus limitaciones y bondades a la hora de seguir el movimiento de la sociedad en términos de disputa bajo una sistemática basada en la prensa (Franzosi, 2017; Ghigliani, 2009; Sorribas, 2010; Stiberman, 2017).

Nos referimos a dejar el lugar periférico que generalmente tiene la explicitación de los métodos y las técnicas en nuestras investigaciones, para tornarlas una preocupación en transferir modos de acercamiento al fenómeno y sus implicancias teórico-epistemológicas.

Para ello partimos de un camino configuracionista (De la Garza, 2018), que recorre las instancias de lo abstracto-concreto en el modo de exposición, en tanto este camino -a diferencia del método de investigación- es considerado por Marx como el "aspecto científico del método", en el sentido de ser capaz de una sistematización mayor, fase que va de lo abstracto al concreto pensado, reconstrucción teórica del objeto y explicación del mismo. Es la presentación (conceptualmente) ordenada de un complejo caótico previo (De la Garza, 1983).

De ello se desprenden los lineamientos que seguiremos aquí: en la primera parte recorreremos discusiones teóricas acerca del sentido del conflicto, es decir, tomaremos el quéde su constitución como objeto de estudio. En la segunda parte, desarrollaremos un nivel de concreción mayor, el concreto-históricamente determinado, mediante el análisis del conflicto en la configuración socioeconómica, la dinámica de su desarrollo y las tradiciones de lucha en nuestra provincia. En el tercer apartado, precisaremos conceptualmente las formas de manifestación de la subjetivación política: las acciones conflictivas que se visibilizan en el espacio público y que ponen de manifiesto cómo y qué demandan quienes luchan. Para finalizar, pretendemos retornar a las preocupaciones iniciales: qué se puede conocer y cómo del antagonismo capital-trabajo con las herramientas diseñadas, con las que pretendemos componer la totalidad (concreto-abstracto-concreto) para desentrañar algo más allá de la conflictividad, que está "tan a la vista, que no se ve". 


\section{El CONFLICTO COMO OBJETO DE ANÁLISIS (EL ABSTRACTO-CONCRETO)}

Nuestra propuesta se inscribe en la tradición de estudios del marxismo, según la cual las relaciones de producción del capitalismo conforman la causa del antagonismo que surge de las condiciones sociales de vida de los individuos, mientras que las fuerzas productivas que se desarrollan en el seno de la sociedad burguesa crean, al mismo tiempo, las condiciones materiales para resolverlo (Marx, 1982, p. 67). En esta línea, la discusión dentro de esta tradición reconoce dos planos de análisis: uno abstracto que debate la cuestión de la relación capital-trabajo y otro concreto, a nivel de las formaciones sociales de referencia, es decir, en un determinado espacio-tiempo. La lógica de estos planos es sintetizada por Izaguirre (2014):

(el) teórico-abstracto (...) nos informa de la existencia de dos grandes conjuntos humanos en el capitalismo, en oposición antagónica, con intereses contrapuestos, que se constituyen en sus confrontaciones (...) En el otro plano, histórico, analiza el desarrollo concreto de cada uno de los referentes conceptuales: burguesía, proletariado, pequeña burguesía, y otras fracciones sociales; y muestra que difieren -según el período histórico... (p.15)

Por tanto, nuestra propuesta se centra en el significado del cambio epocal al que asistimos en relación al "claseamiento de lo social", con el objeto de encontrar un plano intermedio que articule aquella gran contradicción con su expresión histórica, expresada en "conflicto". En este marco, ubicamos la resignificación del concepto de clase, a la vez como posición y movimiento, donde se recuperan para comprenderlas las prácticas y experiencias en términos de "subjetivación política".

A pesar de las resignificaciones del concepto de clase, desde los años 60, en términos de "disposición a actuar como tal" (Thompson, 1989), esta perspectiva no predominó entre las investigaciones que daban cuenta del conflicto social. Las mismas estuvieron marcadas por las corrientes norteamericanas de la "movilización de recursos" o de la "acción colectiva" y las europeas, atinentes a los "nuevos movimientos sociales", o su síntesis, las "teorías de las oportunidades políticas". Todas ellas distantes de mediar la reflexión entre los planos analíticos que marcaban la impronta del capitalismo actual para ausentarse de la "clase" y virar hacia nuevas problemáticas (Touraine, 1987; Melucci, 1989; Offe, 1992; Tarrow, 1997, entre otros)².

Mientras tanto, las perspectivas críticas, cuyo arsenal conceptual recuperaba las categorías centrales y clásicas del marxismo, clase y lucha de clase, no dejaron de presentar ciertas debilidades operativas a la hora de "mediar" los planos mencionados u "operacionalizarlos".

Por ello, como Observatorio nos trazamos ciertos objetivos relevantes de mayor amplitud (que trascienden el mero instrumento cuantitativo, sin desmerecer su importancia analítica), que implican el análisis de las subjetividades políticas que se configuran a la luz de la dinámica del conflicto. Para ello es necesario realizar una operación teórica que articule las categorías de clase, conflicto y subjetivaciones políticas como clave explicativa para la especificidad del campo de los estudios críticos del trabajo.

La recuperación de conceptos y postulados críticos no implica desconocer la necesidad de establecer puentes operativos en diálogo con el arsenal de otras teorías, en un nivel intermedio y empírico, para enlazarlas con categorías marxistas en un plano de mayor abstracción. Aquí la tarea analítica de "hilvane" o reconstrucción de la totalidad es una labor ineludible de quien investiga. Con ello queremos despejar la pretensión de que el instrumento de medición resuelva "mágicamente" nuestras falencias teóricas. El llamado es doble: no convertir la técnica en un artefacto o fetiche serial productor de datos, y tampoco exigirle que supla "el trabajo del y con el concepto".

Vale recordar que para Marx, conocer es transformar intuiciones y representaciones en concepto y es en la praxis donde surgen las mismas que deben ser volcadas en conceptos. Esta concepción rechaza simultáneamente la consideración de lo real como el resultado del pensamiento que se reabsorbe en sí mismo y los postulados del empirismo que toman por objeto científico el objeto "real" en su totalidad concreta, sin advertir que este procedimiento no hace más que asumir las abstracciones del sentido común, negándose 
a realizar el trabajo de abstracción científica que implica siempre una problemática histórica y socialmente constituida (Gutiérrez, 2003).

La abstracción, como método, trata de la descomposición del todo (concreto real), en el pensamiento, por medio de conceptos. Es forzosamente un producto del pensamiento y un paso "inevitable" en la construcción de conocimiento. Es decir, pretende reducir la "plenitud concreta de lo real a su expresión abstracta en la conciencia; es la condición sine qua non de toda investigación" (De la Garza, 1983, p. 21). Por tanto, no son aislamientos de elementos, sino reconstrucciones de la totalidad y en la explicación de esta pueden intervenir categorías de diversos grados de abstracción (Por ejemplo: modo de producción, formación social y coyuntura).

El proceso de abstracción es un momento de investigación -el intermedio y necesario- que hace posible pasar del concreto representado al concreto síntesis, o totalidad, con múltiples determinaciones. Mientras menos abstracta sea la totalidad (o concreto síntesis) que se busca construir a nivel del conocimiento, el análisis deberá incorporar mayor cantidad de categorías, conceptos y relaciones de los niveles más abstractos, al tiempo que requerirá de categorías particulares y de metodologías específicas para alcanzar sus fines. De ahí que, a un menor nivel de abstracción pasemos a mayores niveles de complejidad. En este proceso, el método no existe por fuera del contenido; es la manera en que el mismo contenido va revelándose y asumiendo una forma racional a través de la investigación (Osorio, 2004)

Hecha esta breve disquisición epistemometodológica, es necesario situarnos en nuestro objeto de análisis: el conflicto, sus significados y las disputas de sentido que encarna. Como buena parte de los conceptos en ciencias sociales, el mismo porta diversas connotaciones y categorías asociadas. Así, Maliandi (2010) expresa "las vecindades semánticas" entre conflicto y otras nociones asociadas tales como: antagonismo, oposición, antinomia, contradicción, luchas. Sin embargo, considera que -en términos conceptuales- el más abarcativo en su extensión es conflicto, ya que involucra no solo la lucha efectiva sino también las tendencias a ella (en tanto preparación o disponibilidad para la lucha). ¿Y qué significa luchar? En su definición evoca un pasaje de Kundera: "luchar es enfrentar la propia voluntad a la voluntad de otro con el propósito de doblegarlo, ponerlo de rodillas, eventualmente matarlo" (p. 33). Es una "lucha por algo" y "contra algo". Ese contra, define una posición con respecto a algo y a alguien, es una o-posición. En este sentido, los conflictos son formas de oposición. Las oposiciones conflictivas son dinámicas, porque existen tensiones y tendencias a la exclusión. Todo lo que tiende al orden representa simultáneamente un factor de inhibición de la conflictividad (Maliandi, 2010, p. 27).

Esta definición nos sirve teórica y operativamente, pues contiene los elementos que a priori interesa sondear: un protagonista con disposición a la lucha (sujeto colectivo subalterno); un antagonista (quien confronta o se opone al primero) y un bien que está en disputa. ${ }^{3}$ Es decir, nos interesa presentar el conflicto como unidad de análisis (espacial y temporal densa), que se articula en sus distintos niveles de abstracción con otras categorías de menor espesor analítico como la "acción conflictiva", que desarrollaremos en un próximo apartado.

Particularmente, en este sentido, los aportes de Modonesi (2010) sobre la tríada conceptual subalternidad, antagonismo y autonomia se tornan relevantes para la comprensión de la conflictividad en la conformación de las subjetividades políticas de (en nuestro caso) "trabajadores/as que luchan", que connota la situación de la clase "en movimiento".

En este sentido, la categoría de subjetivación política (más concreta que las nociones de clase y lucha de clases) posibilita un acercamiento a "las formas y las dinámicas de conformación de subjetividades políticas en torno a (...) experiencias colectivas surgidas de relaciones de dominación, conflicto y emancipación” (p. 15).

A partir de las contribuciones de Negri, Modonesi plantea que el antagonismo remite a dos acepciones: una general, como sinónimo de contradicción, y otra particular, vinculada al conflicto entre capital y trabajo (con énfasis en el aspecto estructural de la relación), y el enfrentamiento de clases (con hincapié en el aspecto subjetivo). Es decir, el antagonista es el sujeto que se configura en el conflicto. 
De este modo, rescata del autor italiano el desarrollo de dicho concepto en su acepción subjetiva, dado que posibilita reconocer el proceso de conformación de subjetividades en el conflicto, la incorporación de la lucha y las experiencias de insubordinación caracterizadas por la impugnación de la dominación y por el establecimiento y ejercicio de un contrapoder (Modonesi, 2016).

En consecuencia, es relevante la distinción entre resistencia y rebelión, como acciones defensivas u ofensivas, en cuanto a su dimensión temporal, intensidad, frecuencia o recurrencia. La resistencia, como acción política, no deja de expresar la condición de subalternidad, en cuanto no es posible rebasar las fronteras de las relaciones de dominación. Es una renegociación de los términos/reglas del mando-obediencia. En tanto, la rebelión es la expresión del antagonista, en la medida que puede quebrar dichas reglas de juego, pone en crisis -al menos transitoriamente- la dominación. Vale aclarar, no obstante, que ambas nociones son formas de luchas; dirá Modonesi, modalidades diversas de un mismo tipo de práctica social.

Por lo cual, entendemos que el campo analítico de "la clase" no es la forma social grupal o colectiva que asume la coerción estructural, sino la forma en que los sujetos enfrentan dichas coerciones. Es un campo de prácticas de lucha e intervención por el control de las condiciones de existencia material y simbólica frente a otros (Gómez, 2014, p. 27). Su análisis dinámico supone que la condición de clase se constituye en el conflicto y que es a través del proceso de luchas que las posiciones estructurales asumen el carácter clasista o no. En este sentido, Gómez - parafraseando a Luhman- señala que la sociedad se describe a sí misma a través de los conflictos: "no hay instancia social más clasificante que la lucha colectiva" (p. 28).

En la misma línea, Balibar (1991) sostiene que la existencia y la identidad de clase son efecto tendencial de su lucha, lo que abre paso a la cuestión histórica de su transformación y ubica al trabajo como la relación social fundamental, fuera de la cual todas las relaciones políticas permanecerían ininteligibles, ya sean concebidas como contractuales o como puras relaciones de poder. En este sentido, cobran potencia los estudios de los "historiadores ingleses\# (Thompson, 1989; Hobsbawm, 1973), quienes enfatizan la importancia del universo de significados compartidos, de formas de vivir y sentir las relaciones de explotación y opresión, que no son reducibles a efectos estructurales. Es decir, "hacerse clase\# - no como un a priori a deducir- sino como la posibilidad de comprender que, no todas las formas de resistencia pueden ser consideradas como expresión de la lucha de clase, aunque se encuentren atravesadas por la relación capital-trabajo. Si en el enfrentamiento en las relaciones de producción y apropiación del plusvalor se oponen como realidades colectivas, podremos hablar de clases.

En relación con lo expuesto, es dable señalar que las mutaciones actuales de la relación capitaltrabajo se expresan en innumerables procesos (heterogeneidad de posiciones sociales que el capital fomenta en relación a la división global del trabajo, cambios técnicos en la organización del trabajo, deslocalizaciones y recomposiciones en el proceso productivo y de valorización, transformaciones tecnológicas/comunicacionales y labilidad de fronteras entre los ámbitos de producción, distribución, consumo y reproducción), que han conmovido, de manera directa, los procesos de lucha y conflictividad en el trabajo. Sin embargo, las experiencias concretas llevan a diversas formas de enfrentamiento y acciones colectivas -tradicionales o novedosas- en los espacios de trabajo, como marcas de la insubordinación del trabajo frente al comando del capital. Muchas de estas experiencias -en clave thompsoniana (1989)comparten la explotación más que experiencias de lucha. Por esto, nos interesa recuperar la perspectiva de Marx, que sostiene que "los diferentes individuos solo forman una clase en cuanto se ven obligados a sostener una lucha común contra otra clase, pues por lo demás ellos mismos se enfrentan unos con otros, hostilmente en el plano de la competencia" (Marx y Engels, 1968, p. 60). Por tanto, la lucha se torna un indicador sintomático, ya que es refractaria de la competencia y permite la gestación de procesos de colectivización.

De este modo, los conflictos marcan la emergencia y disrupción de la contradicción entre capital y trabajo en un plano concreto. Como tensión permanente, evidencian las fuerzas que -en un momento y por ciertos acontecimientos- detentan cada uno bajo múltiples determinaciones. Sin embargo, como mencionamos previamente, no toda expresión de conflicto impugna el orden laboral o favorece a los intereses de la clase 
trabajadora. Para ello es necesario ubicarse en el carácter de las reivindicaciones/demandas, las cuales pueden evidenciar una normalización de la insubordinación o una tendencia a la mejora en relación a los intereses de clase (Collado y Roitman, 2015). Es decir, la composición de la clase trabajadora se torna un elemento central a la hora de investigar la conflictividad y sus expresiones, más allá de la posición en la estructura productiva y ocupacional.

Por ello, es necesario analizar los conflictos en relación con un conjunto de dimensiones situadas históricamente para considerar cuándo los mismos precipitan en acciones colectivas o las abortan; cuándo las formas de organización de los colectivos de trabajadores y la de sus ámbitos de representación emulan la gestión del capital o se abren posibilidades para el cambio y la ampliación de redes y tramas de solidaridad.

\section{LOS PROTAGONISTAS: CAPITAL-TRABAJO (EL CONCRETO PENSADO HISTÓRICAMENTE)}

El conflicto puede ser descifrado en un campo de relaciones de fuerza, situado y datado (Gramsci, 1973). Pero ese “concreto-real” (De la Garza, 2018) es caótico y, por tanto, necesita precisión (categorías de mayor nivel de abstracción que simplifiquen a la vez que avancen en una sistemática). Por ello, el acercamiento por la vía de categorías debe atender a dos cuestiones fundamentales: 1) expresar relaciones reales; 2) estar históricamente determinadas. De la configuración de relaciones posibles a ser investigadas a propósito de la conflictividad laboral, el dilema se dirime entonces en escoger un haz de aquellas que posibiliten la aproximación "eficaz" al proceso social en estudio. Evocamos a Thompson en nuestra ayuda:

La experiencia de clase está ampliamente determinada por las relaciones de producción en las que los hombres nacen o en las que entran de manera involuntaria. La conciencia de clase es la forma en que se expresan estas experiencias en términos culturales: encarnadas en tradiciones, sistemas de valores, ideas y formas institucionales. Si bien la experiencia aparece como algo determinado, la conciencia de clase no lo está (Thompson, 1989, pp. 13 y 14, cursivas nuestras).

Aquí aparecen aspectos que se deben sondear a fin de comprender el conflicto y que anudan en la experiencia de la conflictividad. Uno de ellos nos lleva a las "relaciones de producción" (materialidad de la situación del trabajo) y el otro a la "conciencia de clase" (su politicidad). Desbrocemos a continuación sus implicaciones.

El acercamiento a las relaciones de producción nos sitúa en un nivel sociohistórico, en que se conjuga la dinámica de la acumulación del capital y las formas en que esta es garantizada por el Estado o, en otras palabras, su forma "gubernamental", "Estado Ampliado" o "sociedad civil" (Gramsci, 1981, p. 357). Estas sintetizan la impronta singular de cada espacio social (economía regional), en función de su historicidad y es en este plano que la historia incide en las decisiones metodológicas acerca de la comprensión-interpretación del "objeto" (el objeto "conflicto" comienza a determinarse de modo concreto en los sujetos intervinientes). Veamos cómo la variación de nivel de abstracción opera en nuestro caso.

La singularidad de la acumulación "mendocina" se ha cimentado históricamente en la riqueza de petróleo en combinación con la vitivinicultura. La actividad petrolera, denota baja intensidad de ocupados/as, de alta calificación, concentrados en refinería y pozos. Mientras tanto, en la vitivinicultura el plantel trabajador se mueve a dos bandas: una porción mayoritaria se dispersa en cada oasis de cultivo, con mano de obra estacional, migrante y/o golondrina altamente informalizada, y una porción menor que se concentra en trabajadores estables de bodega, de mayor calificación, sobre todo luego del pasaje del "modelo de cantidad" al "modelo de calidad" (Altschuler, 2017; Mateu, 2011).

Esta configuración produjo en la "población que vive del trabajo", una considerable dispersión territorial o la inexistencia de un cordón "obrero-industrial" o de grandes "colectivos de trabajadores", partícipes de lo que Soul (2009) denomina comunidades de fábrica. La excepción respecto de "grandes" agrupamientos obreros se sustanció en relación a la megabodega del Estado, GIOL (Garzón Rogé, 2011). En relación a los 
petroleros, su sindicato (SUPE) reconoce escasa tradición combativa y un perfil que, a fines de siglo XX, con la privatización de áreas, viró a un eficaz “sindicato de negocios” (Muñiz Terra, 2006).

Paralela a la reconfiguración productiva provincial se verifica una paulatina y sostenida terciarización de la economía desde los años 90. En este nuevo escenario, el mayor número de ocupados pertenecen a las ramas del comercio y servicios sociales y personales (Canafoglia, 2010). Esto refuerza la disgregación, ahora de la mano del sector privado, por su ubicación en establecimientos pequeños y medianos con bajos niveles de organización y conflictividad.

El tercer conglomerado laboral de envergadura son los trabajadores del Estado. Los estudios sociohistóricos locales registran una importante tradición de luchas, sobre todo de docentes y agentes de salud, quienes han protagonizado a lo largo del siglo pasado ciclos significativos de beligerancia (Baraldo y Scodeller, 2006; Bertolotti, 2012).

Aquí merecen una mención especial las experiencias de organización territorial, protagonizadas por trabajadores marginados. Su génesis reconoce hitos desde el "Mendozazo" (1972) pasa por las puebladas de los noventa frente la hiperinflación (la movilización de las llamadas "zonas rojas”), y llega hasta hoy, en la conflictividad territorial que muestran quienes viven de la "ferias".

En este escenario en que los sujetos intervienen en la trama social munidos de sus trayectorias sociohistóricas, es necesario hacer asequible la heterogeneidad a la que hacemos alusión cuando hablamos de trabajadores. Para ello retornamos a la reconstrucción metodológica del concreto-histórico que acabamos de sintetizar, para dar pie al concreto-pensado (las variables y dimensiones que darán cuenta del mismo), para establecer nuestra población bajo análisis. Recurrimos, una vez más, a los lineamientos de De la Garza (2018):

En la fase de la investigación, en la que se privilegian las funciones reconstructivas de los datos sobre las verificativas, y que es a la vez una etapa menos sistemática que la de la exposición, la cuantificación puede cumplir un papel que podrá ser más importante en los momentos de arribo a la categoría más simple, dentro de la idea de que el avance en lo empírico de lo concreto a lo abstracto, se traduce en otro de lo específico a lo general (p. 319)

$\mathrm{Si}$, tal como anticipamos, nuestro "objeto" es el conflicto, el foco fundamental son los que confrontan capital-trabajo. Cabe preguntarse entonces, ¿qué incluye esta primera circunscripción? Asumir esta cuestión nos llevó a debatir en torno a la significación de las personificaciones del trabajo o, más extensamente, de quienes viven de su fuerza laboral, bajo el comando del capital.

Entran aquí asalariados clásicos y no clásicos (De la Garza, 2017), los trabajadores formales e informales, visibles e invisibilizados, citadinos, rurales y periféricos. También está incluido el universo de los que padecen una relación salarial o de dependencia “disfrazada" a través de nuevas modalidades contractuales que menoscaban la relación laboral. Tal como acierta a reafirmar van der Linden (2008), integramos aquí a:

Cada portador de fuerza de trabajo cuya fuerza de trabajo es vendida o alquilada a otra persona en virtud de una compulsión económica o no económica pertenece a la clase de trabajadores subalternos, independientemente de que el portador de fuerza de trabajo esté en venta o alquiler e, independientemente de que el portador mismo sea propietario de medios de producción (p. 111).

La delimitación anterior se abre, en nuestro caso, para comprender a un grupo que no es estrictamente asalariado y que se explota a sí mismo. Dentro de este núcleo integramos a propietarios de transportes (con capitales menores); empresas que no involucran planteles de trabajadores a cargo (salvo familiares); los microcomerciantes, $\mathrm{y}$-en nuestra provincia una población relevante- los pequeños productores agrícolasvitivinícolas. En este grupo incluimos a los viticultores que por escala, tipo de producción y posición en la cadena de valor conforman capital subalternizado en la cadena agroindustrial (Altschuler, 2017).

Segunda cuestión, estas personificaciones del trabajo no interesan en cuanto individuos, sino en su expresión colectiva-experiencial-práctica, por tanto, las manifestaciones de conflictividad individuales no son captadas para su análisis. 
Los modos de agregación de los sujetos colectivos darán cuenta, a la vez, del momento en que se sustancia la experiencia de la lucha y que se expresa en su politicidad. Esta cuestión, en este caso, denota si los trabajadores desbordan por las bases a las direcciones tradicionales, si se expresan solos como movimiento y sin organización visible, si se agregan en sus organizaciones sindicales clásicas o si se vinculan con otros sectores socioocupacionales afines y extienden su programa, más allá de intereses corporativos, y, de hacerlo, hasta dónde llega dicha articulación. De este modo, las variables que empíricamente caracterizan al sujeto protagonista de las acciones y a sus dimensiones registrarán trabajadores que luchan como "movimiento de bases" o "sindicatos". En este mismo registro se pondera el alcance de su articulación con otros colectivos, pues de ellas se desprenden las alianzas, tanto como el rebasamiento (o no) de sus intereses corporativos (federaciones, multisectoriales y centrales sindicales). Otro aspecto que caracteriza la incidencia de los sujetos en conflicto es la escala espacial e institucional que los contiene, ya que desde este marco se muestra otro indicio de los alcances de su accionar. Con respecto al primero, su registro remite al lugar en el que litigan (local, municipal, provincial, nacional), y con respecto al segundo, al área socioeconómica de inserción laboral (rama de actividad, varias ramas económicas, sector económico). Ambas dan cuenta de la "escala" del conflicto.

Hasta aquí hablamos nuestros sujetos en términos de personificación y agregación colectiva, en dos niveles de concreción de la misma abstracción: el trabajo. Delineado lo anterior, sus dimensiones espaciales abrevan en la caracterización de su organización, alianzas e incidencias (Lefebvre, 2013).

Con dichas connotaciones nos importa conjugar la problemática local sondeando sus especificidades, a sabiendas de que su "configuración" se encuentra inmersa en una red mayor de interdependencias (Elías, 1987). Tal vez este sea el mayor desafío: que la caracterización puntual sea relevante en tanto y en cuanto se articule con la situación y derrotero general de los trabajadores. El "salto" del proceso concreto al análisis e interpretación del mismo es lo que hace significativas las vinculaciones entre empiria y teoría; variable y categoría, o lo que de la Garza denomina la conformación del "objeto virtual”:

producto de la articulación por niveles de la realidad (potencialidades de lo concreto a lo abstracto), de categorías que expresen relaciones probables. (...) El punto culminante de la construcción del espacio de lo posible se alcanza cuando en la última categoría se sintetizan las contradicciones de las anteriores, abriéndose la posibilidad de un viraje en la dirección del proceso (De la Garza, 2018, p. 159).

La interpretación y la conexión del proceso empírico con la teoría conforma el trabajo artesanal de quien investiga, que, sin soportes básicos como lo son la teoría social y la historia, no puede vislumbrar más que un objeto opaco o una multiplicidad de destellos que obnubilan su comprensión.

\section{EL PESO EMPÍRICO DE LA ACCIÓN CONFLICTIVA Y LA CARGA TEÓRICA DE LOS DATOS}

Como vimos anteriormente, la articulación entre teoría e historia nos ayuda a componer un conjunto de dimensiones y a tomar ciertas orientaciones en la configuración del conflicto laboral, en un plano de mayor concreción. Pero nuestro interés no es construir una herramienta de análisis del pasado sino una que extienda la interpretación a lo que está por advenir. Dice Zemelman al respecto:

En realidad, si lo que importa es la capacidad de reconocer horizontes históricos (de manera de ver la potencialidad de la realidad) nos obligamos a incorporar la dimensión volitivo-social en el estudio de las dinámicas sociohistóricas. El análisis de las situaciones históricas incorpora la voluntad, ya que la consciencia deja de ser el reflejo de las tendencias históricas para transformarse en la capacidad para reactuar sobre lo inmediato (2011, p. 89).

¿Cómo captar, entonces, la voluntad a través de una herramienta de testeo cotidiano del conflicto con fuentes que primen su visibilización (es decir, la publicidad de esos actos) y no anclen en el propio sujeto? Para nosotras la voluntad pasa a ser un acto de expresión de los sujetos colectivos, que denominamos “acción conflictiva”. Esta se impone como anudamiento de la situación en que los sujetos están en el presente, aquello 
que quieren lograr a futuro (o el bien que está en disputa) y los medios/recursos necesarios para obtenerlo (el transcurrir). La acción conflictiva se materializa en "la noticia", en tanto registro de prensa y sobre la que sistematizamos toda información sobre los sujetos en disputa. ${ }^{4}$

Por todo ello la acción conflictiva es a la vez unidad de registro y de análisis, elemento básico en el que se engarza un proceso que expresa "tipos de acciones" y que conforman repertorios para canalizar sus demandas.

Las acciones expresan lo voluntario-consciente de tales experiencias, en el camino que marca Modonesi (2016) al aludir a las prácticas como formas y dinámicas en cuatro niveles:politización (formas de agregación y enunciación); organización (formas de participación y deliberación); movilización (formas de manifestación y difusión); realización (formas de articulación, negociación y autonomización). Esto significa que captar las mismas nos aproxima a la politicidad de los trabajadores, la subjetivación política denotará el grado de disposición a actuar de la clase tanto como el nivel de relaciones de fuerzas al que asistimos: "las subjetividades políticas son combinaciones desiguales de subalternidad, antagonismo y autonomía (...) descifrar su composición implica una operación de ponderación relativa que establezca el peso y el valor de cada dimensión frente a la otra" (p. 63)

Así, de la reconstrucción de un concreto-pensado pasamos a su apertura para hacerlo empíricamente observable. Recapitulando, los niveles de análisis que operan en una misma categoría hasta ahora son tres: el más abstracto, el conflicto; su elemento de observación, la acción conflictiva, y sobre esta última reconocemos sus dimensiones: los tipos de acción. Finalmente, con el conjunto de los resultados podemos reconstruir un panorama secuencial de despliegue de la conflictividad.

La tipología de las acciones conflictivas, sin embargo, no conforma solo un sistema clasificatorio, sino de "gradaciones" que expresan la profundidad e impactos de la protesta (por ejemplo, solo paro, solo asamblea, asamblea-paro-movilización juntas), y que en vinculación con otras características (duración, extensión, integración institucional, sector de actividad económico e institucional afectado) y de los sujetos (solo bases; bases y sindicatos; multisectoriales) configuran la intensidad de las demandas y las fuerzas que despliegan los sujetos colectivos.

Como vimos, el abanico que tipologiza las acciones (más de una veintena: asamblea, paro, movilizaciones, trabajo a reglamento, piquete, ocupación de fábricas/empresas, entre otras) es importante por sus derivaciones práctico-políticas, pues marca hasta dónde llega intencional y conscientemente la acción colectiva.

Con estos datos, sumados a la caracterización de los sujetos y a quiénes estos se enfrentan, podemos establecer el cuadro de situación de relaciones de fuerzas en un específico espacio-tiempo.

Para ello falta componer el plano de la hegemonía. Si bien la captura de la misma en el Observatorio es menos enfática que la de la subalternidad, de modo sucinto, la caracterización de los antagonistas nos posibilita acercarnos a las formas de construir consensos o conjurar la coerción, y nos pone de lleno en las tácticas y estrategias del "sector dominante". De allí que importen las respuestas del Estado o el mercado frente al conflicto en sus diversas manifestaciones: la agregación del sector dominante (sector afectado institucional, de actividad y sus organizaciones representantes); los repertorios de acción utilizados (más o menos legales, legitimados e institucionalizados para hacerle frente), la puesta en función de mediadores (lo que aproxima a la valoración de su dominio, el ejercicio de su dirección y/o su deslegitimación), y las formas que adopta la criminalización a fin de repeler, docilizar y/o encauzar los desbordes del conflicto y sus sujetos.

Con esto queda establecido el campo de lo que está en disputa en la escena pública: fuerzas en pugna, subjetivaciones políticas y modos de repulsión-respuesta de los sectores dominantes, todo en una sucesión de acciones conflictivas que se anudan en un conflicto y que temporalmente permitirán apreciar un "ciclo". Nada más y nada menos que la construcción de datos cuya estructura admite la articulación necesaria de cinco aspectos: teorización e historicidad, unidad de análisis, variable, valor, síntesis del camino investigativo. Sin las primeras, no puede establecerse la pertinencia de las demás y su densidad para interpretar lo así construido. 


\section{RefLeXiones Finales}

Este trabajo pretendió identificar el camino metodológico a propósito de la construcción del Observatorio de Conflictividad Sociolaboral de la Provincia de Mendoza. Uno de los aspectos centrales a destacar refiere a la ineludible imbricación entre perspectivas epistemológicas-teóricas, construcción de la técnica y resultados.

Para ello partimos de la significación del conflicto capital-trabajo, en un nivel mayor de abstracción, para dilucidar cómo se constituye nuestro objeto de estudio. Luego intentamos variar el nivel de la problemática, transitando la complejidad de los procesos sociohistóricos, en los cuales cada disputa presenta una emergencia sincrónica y un despliegue diacrónico con respecto a las demandas, tradiciones de lucha y la configuración de sus sujetos.

En el plano empírico-operacional reflexionamos sobre algunas de las dimensiones y sus variables. La lectura e interpretación de las mismas da lugar a la caracterización de la subjetivación política quienes luchan: subalternizados, antagonistas o autónomos.

Estas subjetivaciones políticas van desplegando acciones que deben ser explicadas en su marca témporoespacial para definir ciclos y situaciones de recrudecimiento y decrecimiento del conflicto. Frente a ello, la conformación de los grupos hegemónicos da respuesta, y su descripción colabora a conformar los marcos que posibilitan o constriñen el accionar de la subalternidad.

Los sujetos y sus vínculos configuran las "relaciones de fuerzas" que se sustancian en el espacio de una formación social concreta -Mendoza-, y que deben necesariamente articularse con otras demarcaciones mayores para colaborar a una "restitución de la totalidad" -siempre heterogénea- acerca de una caracterización de los conflictos más acabada de quienes viven del trabajo hoy en nuestro país.

Por tanto, construir una técnica sobre la cotidianeidad de los conflictos laborales nos enfrenta no solo al dilema de cómo y qué conocer (en qué medida se puede sistematizar el seguimiento de un proceso), sino al de analizar el sentido de la conflictividad. Tal como hemos visto, este sentido se encuentra embebido en una cultura, una configuración de relaciones de luchas y una trayectoria perpetrada por los sujetos antagonistas (genealogía del conflicto), cuya disputa se inscribe en un determinado tiempo y espacio. En nuestro caso pensamos observar de modo situado, de allí que una de las decisiones centrales fue la de tomar conflictos provinciales (cuya parámetro de observación es Mendoza y/o la participación de actores en su territorio) 5 .

Luego de la experiencia abierta por la crisis del 2001 no era posible reflexionar acerca de los conflictos "nacionales" sin anclaje en los territorios. Esto no apunta meramente a adscribir a la "territorialización de los conflictos" (Svampa, 2008), sino a la posibilidad de analizar las contradicciones de la dinámica del capital, cuya singularidad es regional y se expresa de modo distintivo en cada formación social. Pero, sobre todo, en relación a lo político, el conflicto es generado por el "desacuerdo" entre esa dinámica y la población que, a propósito de la misma, se torna sujeto.

Siguiendo estas claves, el pulso del Observatorio nos permite establecer la apertura y cierre de ciclos de conflictividad laboral, las principales características de los trabajadores que luchan (y por ende, aquellos colectivos que "no luchan"), las connotaciones de sus demandas y sus repertorios de acción, así como determinar sus antagonistas, mediadores y los modos de control-encauzamiento por parte del Estado. En esta línea sí existe un interés -o al menos un recorte- que asume el espacio público como inscripción de las acciones colectivas a partir de demandas que dan visibilidad a ciertas formas de acción. También, sobre todo en el último trienio, se ha dado lugar a la puesta en cuestión de la fuente utilizada (medio de comunicación hegemónico), habida cuenta no solo del sesgo histórico que marcan los investigadores que utilizan las mismas y que hemos mencionado, sino a su desborde y enriquecimiento en la consideración de otras fuentes, tales como redes sociales o medios de comunicación alternativos.

Finalmente, y como balance de lo hecho hasta aquí, podemos sostener que "observar" ha demostrado su pertinencia y potencialidad en la producción de conocimiento acerca de un proceso tan complejo como dinámico y cambiante. Y que si bien la observación es central, se nutre necesariamente de un arsenal de otras 
técnicas de construcción de datos, lo que potencia su capacidad de descripción e interpretación del proceso, más allá de la reducción a su concepción de matriz cuantitativa.

\section{REFERENCIAS}

Altschuler, B. (2017). Asimetrías y fronteras sociales en la configuración de la vitivinicultura mendocina. Revista de Estudios Sociales Contemporáneos, 16, 81-109.

Baraldo, N. y Scodeller, G. (2006). Mendoza "70 tierra del sol y de las luchas populares. Mendoza: Manuel Suárez.

Balibar, E. (1991). ¿De la lucha de clases a la lucha sin clases? Madrid: IEPALA.

Becerra, M., y Mastrini, G. (2011). Estructura, concentración y transformaciones en los medios del Cono Sur latinoamericano. Comunicar, 36 (XVIII). 51-59.

Bertolotti, M.F (2012). El Mendozazo. Herramientas de rebeldia. EDIUNC: Mendoza.

Canafoglia, E. (2010). Situación actual y desafíos para el desarrollo productivo en la provincia de Mendoza. En M. Kulfas, M. Schorr, et al. Postales de la Argentina productiva (pp. 97-114). Buenos Aires: Colecciones del Zorzal.

Collado, P., y Roitman, S. (2015). Más allá de la revitalización sindical: la subjetivación política de los trabajadores. En J. Montes Cató y M. Delfini (comp.), Recomposición del capital y respuestas sindicales en Argentina (pp. 145-176). Bs As: UNGS.

De la Garza, E. (2018). La metodología configuracionista para la investigación. México: Gedisa UAM.

De la Garza, E. (1983). El método concreto-abstracto-concreto. México: UAM.

Elías, N. (1987). El proceso de la Civilización. Madrid: Fondo de Cultura Económica.

Garzón Rogé, M. (2011). Dispersión, lealtad, pragmatismo: itinerario de la experiencia sindical de los vitivinícolas argentinos. En Ana M. Matheu (comp.), Vinos y competitividad agroindustrial. Un largo camino (pp. 279-322). Mendoza, INCIHUSA.

Franzosi, R. (2017). La prensa como fuente de datos socio-históricos: Cuestiones sobre la Metodología de recolección de datos a partir de periódicos. Revista de estudios Maritimos y Sociales, 11, 255-286.

Ghigliani, P. (2009). Acerca de los estudios cuantitativos sobre conflictos laborales en Argentina (1973-2009): reflexiones sobre sus premisas teórico-metodológicas. Conflicto Social, 2(2), 76-97.

Gohn, M. D. G. (2006). Teoría dos Movimientos Sociais. Paradigmas clássicos e contemporâneos. Sâo Paulo: Loyola.

Gómez, M. (2014). El regreso de las clases sociales: clase, acción colectiva y movimientos sociales. Bs As: Biblos.

Gramsci, A. (1973). Notas sobre Maquiavelo, sobre la Politica y sobre el Estado Moderno. Bs. As: Nueva Visión.

Gramsci, A. (1981). Cuadernos de la cárcel. Edición crítica del Instituto Gramsci, a cargo de Valentino Gerratana, T. III y T. IV. México D. F.: Era.

Gutiérrez, A. (2003). Con Marx y contra Marx: El materialismo en Pierre Bourdieu. Rev. Complutense de educación, 14(2), 453-482.

Hobsbawn, E. (1973). La conciencia de clase en la historia. En I. Mészáros (comp), Aspectos de la historia y la conciencia de clase. México: UNAM.

Izaguirre, I., y Aristizábal, Z. (2002). Las luchas obreras 1973-1976. Los alineamientos de la clase obrera durante el gobierno peronista Nuevas consideraciones teórico-metodológicas para el estudio de los conflictos obreros. Bs. As: I.I. Gino Germani; FCS; UBA

Iñigo Carrera, N., y Cotarelo, M. (2001). La protesta en Argentina (enero-abril de 2001). Revista OSAL (CLACSO), 4, 45-84.

Iñigo Carrera, N., y Podestá, J. (1997). Las nuevas condiciones en la disposición de fuerzas objetiva. Documento de Trabajo (5), 1-18. Disponible en: http://biblioteca.clacso.edu.ar/Argentina/pimsa/20110609115143/DT5.pd $\mathrm{f}$

Lefebvre, H. (2013). La producción del espacio. Madrid: Capitán Swing Libros, S. L.

Maliandi, R. (2010). Ética convergente. Fenomenología de la conflictividad. Bs. As: Las cuarenta. 
Marx, K., y Engels, F. (1968). La Ideología Alemana. Montevideo: Ediciones Pueblos Unidos.

Mateu, A. (2011). Vinos y competitividad agroindustrial: Un largo camino. Mendoza: INCIHUSA.

Melucci, A. (1989). Nomads of present. Social movements and individual needs in contemporary society. Londres: Hutchinson Radius.

Modonesi, M. (2010). Subalternidad, antagonismo, autonomia: marxismos y subjetivación politica. Buenos Aires: CLACSO; Prometeo.

Modonesi, M. (2016). El principio antagonista. Marxismo y acción politica. México: Ítaca.

Muñiz Terra, L. (2006). La erosión del poder sindical en un escenario de privatización: El caso del sindicato Unidos Petroleros del Estado (SUPE). Revista Question, 1(12), 1-10. Disponible en http://sedici.unlp.edu.ar/handle/ $10915 / 30304$

Offe, C. (1992). Partidos políticos y nuevos movimientos sociales. Madrid: Editorial Sistema.

Osorio, J. (2004)."Crítica de la ciencia vulgar. Sobre epistemología y método en Marx. Revista Herramienta, 26. 91-109. Disponible en http://www.herramienta.com.ar/revista-herramienta-n-26/critica-de-la-ciencia-vulgarsobre-epistemologia-y-metodo-en-marx

Sorribas, P. (2010). Acciones colectivas en torno a lo laboral. Algunos planteos metodológicos. Boletín Onteaiken, 5(9), 64-75. Disponible en: http://onteaiken.com.ar/ver/boletin9/2-1.pdf

Soul, J. (2009). Procesos hegemónicos y cotidianeidad. Prácticas obreras en la privatización de la Sociedad Mixta Siderúrgica Argentina. Cuadernos de Antropología Social, 29, 85-102.

Stiberman, L. (2017). Conflictividad laboral en Argentina: Una aproximación a las metodologías del Ministerio de Trabajo de la Nación y la Central de Trabajadores Argentinos. Argumentos, 19, 238-273.

Svampa, M. (2008). La disputa por el desarrollo: territorio, movimientos de carácter socio-ambiental y discursos dominantes [exclusivo en línea], 1-31. Disponible en http://www.maristellasvampa.net/archivos/ensayo43.pdf

Tarrow, S. (1997). Poder en movimiento. Madrid: Alianza.

Thompson, E. P. (1989). La formación de la clase obrera en Inglaterra. Barcelona: Crítica.

Touraine, A. (1987). El regreso del actor. Bs. As.: Eudeba.

Van der Linden, M. (2008). Globalizando el concepto de clase obrera. Revista deEstudios Maritimos y Sociales, 1,(1), 103-113.

Zemelman, H. (2011). Configuraciones criticas. Pensar epistémico sobre la realidad. México: SXXI.

\section{Fuentes consultadas}

Base de Conflictos Laborales Ministerio de Trabajo, Empleo y Seguridad Social (MTEySS) http://trabajo. gob.ar/estadisticas/conflictoslaborales/

Observatorio del Derecho Social - CTA http://www.obderechosocial.org.ar/

Programa de Investigación sobre el Movimiento de la Sociedad Argentina http://www.pimsa.secyt.gov.ar/

\section{Notas}

1 Agradecemos a nuestras compañeras de equipo de investigación de la Universidad Nacional de Cuyo y el CCTINCIHUSA-CONICET Mendoza.

2 Para no abundar en la bibliografía sobre estas corrientes profusamente citadas en el campo académico, reconocemos la sistematización de María Da Glória Gohn (2006), a la que añade las características que tales improntas teóricas asumieron en América Latina.

3 En relación a los debates en los estudios del sindicalismo actual y del trabajo importa quiénes luchan y cómo lo hacen en función del interés de "comprobar" la existencia de protagonistas clásicos o la emergencia de novedosos sujetos, el comportamiento de las organizaciones tradicionales o el surgimiento de inéditas formas de recusación del orden laboral 
Revista latinoamericana de Metodología de las Ciencias Sociales, 2020, 10(1), Junio-Noviembre, ISS...

establecido. En tanto, la cuestión de los antagonistas y mediadores ofrece información acerca de la dirección del conflicto y su profundidad: el nivel en que afecta a la gubernamentalidad institucional que intenta regular y canalizar el proceso conflictual (sea el Estado o sea el mercado). Finalmente, en relación a las demandas, advierten en torno a sobre qué se produce la desavenencia, aquello que está en juego. Y ese "sentido del juego" es el que aporta las connotaciones sobre la situación social de determinada coyuntura, embebida en su historia y dinámicas sobre la situación de quienes viven del trabajo.

4 Para el abordaje de la conflictividad pública y abierta se realiza un registro cotidiano de acciones conflictivas a través de la prensa escrita local (Los Andes, periódico de mayor distribución y consumo a nivel provincial). Algunas de sus dimensiones y variables son: identificación y caracterización de la noticia, sujetos participantes (protagonistas, antagonistas, aliados, mediadores), tipo de demandas, repertorios de acción, formas de organización y representación, alcance temporal, territorial, institucional y sectorial, formas de criminalización. Como expresamos oportunamente la fuente "prensa" ha concitado debates arduos sobre sus sesgos y posibilidades en el estudio de conflictividad social y laboral, a los que cabría agregar la relación actual entre líneas editoriales y poder tal como señalan Becerra y Mastrini (2011).

5 El análisis del Observatorio de Conflictividad Sociolaboral de la Provincia de Mendoza, si bien toma la expresión pública en el ámbito local, articula con la Red de Observatorios de Conflictos Sociolaborales (https://observatoriosconflictividad. org/). La misma agrupa a más de nueve nodos de investigadores de universidades públicas nacionales que comparten los mismos intereses. De este modo, los debates propenden a caracterizar la situación nacional, desde las heterogeneidades regionales.

\section{BY-NC-SA}

